\title{
ALK-2 Inhibitor TP-0184
}

National Cancer Institute

\section{Source}

National Cancer Institute. ALK-2 Inhibitor TP-0184. NCI Thesaurus. Code C156729.

An orally bioavailable inhibitor of activin A receptor type 1 (activin receptor-like kinase 2; ALK2; ALK-2; ACRV1), with potential antineoplastic activity. Upon oral administration, ALK2 Inhibitor TP-0184 targets, binds to and inhibits the activity of ALK-2. This prevents ALK2-mediated signaling and inhibits cell growth in ALK-2-overexpressing tumor cells. In addition, in cancer and inflammatory conditions, ALK-2 is upregulated in response to increased signaling of pro-inflammatory cytokines, especially interleukin-6 (IL-6), and enhances the secretion of hepcidin, a peptide liver hormone and a key modulator of iron homeostasis. Blocking ALK-2-mediated pathways in inflammation and cancer leads to a decrease of hepcidin expression and restores plasma iron levels, thereby preventing low serum iron levels and anemia of chronic disease (ACD). ALK-2, a serine/threonine receptor kinase, is constitutively activated due to activating mutations or upregulated upstream signaling pathways in inflammatory conditions and certain types of cancer. 